\title{
PERSUASION IN MEDIA
}

\author{
Alia' Jawad Almagsosi (MA Candidate), Khalida H.Alghezzy (PH.D) Asst.Prof \\ Department of English, College of Education for Humanities, \\ University of Wasit, Iraq
}

DOI: $10.37648 / \mathrm{ijrssh.v10i03.027}$

Received: 15 ${ }^{\text {th }}$ June, 2020; Accepted: 09th July, 2020; Published: 31 st July,2020

\section{INTRODUCTION}

In a broad sense, persuasion could be stated as a literary technique used to influence the audience. Persuasion may simply use an argument to persuade the readers, or sometimes may persuade readers to perform a certain action. Simply, it is an art of effective speaking and writing in which writers make their opinions believable to the audience through logic, by invoking emotions, and by proving their own credibility. The popular philosophers, Plato and Aristotle, set up the reality that individuals require a sense of communication so as to alter anything they need to. Subsequently, the process of persuasion is considered a phonetic apparatus of communication and individuals have free choices to choose since they are represented by their minds and feelings. The method of influence is basically built on three tomahawks, notably the persuader, the persuader, and the influential message .From now on, for such process to be fruitful, the center of consideration isn't only directed on the persuader or the maker, though his/her part is so vital, but rather on the persuader or the collector, and how s/he gets it the displayed persuasive message. Besides, influence is utilized as a apparatus for individual pick up under many public claims. Individuals in control can do such handle, as a result such prepare is so critical in political spaces, the show ponder bargains with political persuasion in race campaigns.

The study aims at investigating the persuasive strategies in English language and showing how people are influenced by the strategies of persuasion.
It is hoped that this study can be advantageous to those who get pleasure in studying the social wrongs and the discursive strategies in a hope to moderate them via linguistic tools of discourse production.

\section{PERSUASION: BASIC CONCEPTS AND DEFINITIONS}

Different lingusits provide diver definetions of persaution from lots of perspectives.Andersen (1971:6) defines it as

"a process of communication by which the persuadee gets his claim from that of the persuader".

Smith (1982:7) recommends that the extreme point of such intentional activity is to impact the approval of modern proposed cognitive state by means of the informed messages. Bettinghaus and Cody (1987:3) depict it as a cognizant endeavor by one individual for the purpose of changing states of mind, convictions, or behavior of another person by the exchanges of certain message. O'Keefe(1990:17) characterizes it as a marvelous intentional way of exerting special effort so as to influence other's mental state by the cruel of communication in case when the persuade is curious about the flexibility of the choice.

Having introduced those definitions, one can easily understand that persuasion is featured by a set of traits, notably that it is a social process of communication, it implies influencing others, it is a conscious activity,and it involves intended message 
(Handayani,2011:4).The nature of this process of communication is achieved between the persuader and the persuadee by means of certain intended message.

\section{PERSUASION AND RHETORIC}

The relationship between persuasion and rhetoric as "wherever there's influence, there's rhetoric. And wherever there's meaning there's persuasion" (Burke, 1969:172). Kennedy (1991:ix) recommends that Aristotle pays consideration to the 'moral' character, or the 'morally neutral' instruments as a key characteristic in influence. He too advances the reasoned contention over the enthusiastic appeals. In addition, Frijda\&Mequita(2000:45) state that Aristotle clarifies the enthusiastic stimulate with influence, warning that feelings ought to not overcome reasoning when he says "The speaker persuades by implies of his listeners, when they are energized to feeling by his speech;for the judgment we provide are not the same when we are impacted by bliss or distress, adore or hate".

Fairclough\&Fairclough (2012:19) suggest that the connection between persuasion and rhetoric is traced back to the time of Aristotle.He offers a considerable relationship between human power of speech, and the intention of changing, generally in different social domains ,and specifically in the domain of politics. Rhetoric and persuasion are deeply intertwined and used when exercising power.

\section{RHETORICAL STRATEGIES OF PERSUASION}

Following Aristotle's explanation that persuasion is a matter of reason or emotion, or both of them, i.e., mind / heart dependency that brings the rhetorical strategies of persuasive arguments into play. The best one implies all the three pillars of appeals which are identified as follows:

\subsection{Etho: The Ethical Appeal}

The etho is an expression which alludes to the moral and ethical character owed on the portion of the persuader. What is accepted is that the picture of the persuader which is seen on the eyes of his gathering of people ought to stimulate the believe and hence create a feeling of great well and intrigued of the persuadee.Aristotle outlines the most characteristics of moral persuader as having intelligence, virtue of discourse, believe , and goodwill towards his audience.Moreover,this identity may be revealed verifiably in argument,for occurrence, reference to the list of services certainly concerning changing the city makes individuals feel emphatically towards such character. Furthermore,Credibility and reliability are of too importance in moral character .(Worthington, 1994:34-36).

\subsection{Pathos, The Emotional Appeal}

It is more centered on the emotional state of the audience; the persuader seeks to use emotions so as to affect his persuadee. Therefore, without it persuasion seems impossible to be achieved. Scholars consider it as the most prominent appeal. Macrus(2000:95) explains that people are motivated in making reasoned decisions in political domain with the emotional appeal. Western (2007: 85-88) mentions that "when reason andemotion collide, emotion invariably wins", i.e.,emotions affect political preferences and cognition and that our response is reflected by emotions more quickly than by reason and rational arguments . Larson(2010:28) clarifies that emotional appeal can be best illustrated by the use of narrative ,i.e., the persuadee is highly affected, motivated, and then taken an action in case if what offers to him takes the form of a tale or a story .

\subsection{Logos, the Rational Appeal}

It alludes to the substance of the intended message of a contention which is presented by the persuader.The issue ought to show consistently and not indiscriminately so as to reach at reasonable and solid conclusion. Aristotle gives this request much of significance than the others. This sort is of vital concern that effects on the audiences' decisions, hence, it is named as a logical argument.The persuader should know the level of his audience before offering his concepts (Larson,2010:7576).Logos relies heavily on the inductive and the deductive reasoning. Whereas the former takes a specific state of fact or issue, then generalized it, the latter takes a broad issue then specifies its 
boundaries. One should notice that in either way the nature of the fact presented should be enhanced with real and credible evidence to save assurance (Wedia\&Stolley,2011:1). Logos implies the internal consistency between the persuasive message, the validity of the claim, the rationality of its reasons, and the effectiveness of its evidence . Aristotle labels it as enthymeme,whereas the study of logic today is called as a syllogism. It is a deductive argument which contains a major premise, a minor premise and a conclusion(Ivan,1989:319). Syllogisms are of three types which are conditional, disjunctive, and categorical ones. According to Larson (2010:222), Conditional Syllogisms are arguments of 'if/then'. Larson mentions that a logical relationship is made between the major premise which is supposed to be in the world and the receivers are to accept and the minor premise that include the existence of one element in the relationship. Then the conclusion comes to exist between such relations. Disjunctive Syllogisms are forms of 'either/or'.The major premise is often accompanied by proofs or evidence in the minor premise.

\subsection{Decision-Making Approach}

Persuasion isn't simple to attain, it depends on how the persuader offers his claim, to which degree he decides his enticing reason, and the level of the persuadee's information concerning the intended message .And over all, the type of interface and inclinations on the portion of the persuader and the persuadee, accordingly. All these matters require a profound thought so as to reach at the point of making choice .This approach is inferred from the theory of intellect around our concern with the other individual.It is grounded on two crucial concepts, namely, thinking and emotion. Thinking starts before even the persuasive interaction begins, then continues at the moment of interaction .It may even goes on at the moment of receiving an information. Emotions are more reactive and easy to be interpreted. These dual activities suggest the most effective course of action and produce four ways of persuasion, according to Matrix persuasive style .Between positivity and negativity of thinking and emotion,this approach comes to exist.The whole issue is built on the intentions, i.e., our concern to others. Both concepts are clarified clearly, avoiding any ambiguity(Strakes(2016:1-3).

\subsection{Positivity of Affection and Reason}

Emotional engagement with others depending basically on the rapport between the persuader and the persuadee, a good one implies sympathy, esteem, and kindness on both sides. One of the important features when presenting argument is that it should not only be tackled intellectually, but rather it should flavor the intellect with the emotional appeal, this is due to the fact that human have natural tendencies to let everything down for the sake of those whom they like.Lincoln's famous statement that 'There's nothing stronger than gentleness' is one of the greatest mean by which the persuader takes gradually the persuade, actually without the latter observes, to the way of determination of decision, hence achieving persuasion . Importantly, the effective persuasion can be best achieved invisibly, i.e., when the persuadee does not recognize that he is persuaded. In the United States, let us say,candidates tend to tackle a midway issues avoiding the divisions and tensions as a stand to be followed, so the importance of the type of the character is more dominant than any other ones so as to appeal to the public (Levine,2003:3-43).In political elections, Perloff(2012:212) says that voting is a matter of heart not of mind.

Reason is considered as the foremost difficult approach since, in sensible contentions, individuals may not necessarily get it and connected the presented points straightforwardly, and after that to be influenced. Others may initially lose the ordinary realities, and thus they may conclusion with multilayer conclusions. So, legitimacy of reason (positive considering) is vital within the sense that people are more influenced with the clarity instead of with the ambiguity of the claim (Strakes, 2012:5).

\section{THEORIES OF PERSUASION}

Persuasion is a sophisticated social and psychological process which is largely connected with communication modes and contexts.Therefore, many theories are devoted to simplify it by means of extensively research.The following papers are 
(IJRSSH) 2020, Vol. No. 10, Issue No. III, Jul-Sep

devoted to present the essential theories in the process of persuasion.

\subsection{Elaboration Likelihood Model(ELM)}

Petty \&Wenger (1999:24-72) display one of the foremost vital theories of social information which centers intensely on influence. The subject of this theory is based on the duality of activity in which two distinctive sorts of influence are connected together depending on the degree of 'elaboration' between them .This degree can be shifted according to the persuadee's capacity in going to the influential message . Thoroughly examination is required to inspiration, i.e., whether the persuadee has the want to lock in in issue which can be tried as tall or moo, on the off chance that no motivation at all; and to the capacity of process data ,i.e., in case of the persuader's information she/he can lock in in elaboration in case s/he knows everything almost the issue. There are certain variables that impact on the level of inspiration .In case of tall involvement, the elaboration is consequently increased.

Depending on the amount of elaboration to the topics, as far, two directions of persuasion come to appear, namely, the central route, and the peripheral one .The central route represents the ultimate outcome of a person's deeply consideration concerning the presented information .One of the factors that affect elaboration concept is that acceptable messages enhance preferable thoughts , i.e., positive thinking; whereas the unacceptable messages create unpreferrable thought ,i.e., negative thinking.It is based on high level of consciousness and effort of elaboration use people can make rational judgment when following their reason. The nature of the person plays a role in this regard, i. e., some have a natural tendency to engage elaboration extensively, by too much thinking, others do not exert any minimum effort to think at all (Scudder,2010:93)

\subsection{Inoculation Theory}

McGurie(1964:222) is the creator of this theory who likens the medical injection of preventing diseases to persuasion in terms of resistance, i.e., biological resistances is the same as persuasion process.A person who is given an injection so as to weaken the
e-ISSN: 2249-4642, p-ISSN: 2454-4671

activity of viruses and strengthen resistance of the disease is as the same as the process of weakening and hence preventing persuasion, and then stimulating resistant.Similarly, when the persuadee is given specific information before communication it allows him to be more resistance.Moreover, to enhance similarity between persuasion and medical inoculation in terms of threatening, i.e., threatening viruses are similar to those of future threatening of persuasion, weakened viruses means weakened counterarguments.

Compton(2012:189) says that when people are introduced to certain argument, they will be able to realize the counterarguments and stand against them. Prior refutation promotes persuasive challenge of either counterarguments or arguments of challenging positions like beliefs and attitudes. Whereas refuting the same arguments are used in the attack later on ,refuting the different ones are not including in the attack, and in either way, the ultimate aim is that of resistance. There are three stages in applying this theory, notably, warning, i.e., people are informed previously for what may happen, weak attack, i.e., weakly attack may be followed by resistance gently, active defend, i.e., people can actively be selfdefending.

\subsection{Cognitive Dissonance Theory}

This theory is contributed to Festinger(1957:252-259) who elaborates the fact that inconsistency of cognitions leads to unwanted motivations or, i.e., dissonance. The amount of dissonance, in relation to certain cognitive state, promotes the psychological conflicts that are clashed between the consistent and the inconsistent cognitions.Therefore, in case of increasing the number and the importance of inconsistency, dissonance will naturally increase as well .Modes which govern the restriction of dissonance can vary, i.e., either to reduce the importance of genuine cognitions,or supplying newly frames of cognitions, or throw away any dissonance, taking into account that the benefit of these modes can be established in case of attitude, belief, value and behavioral change.Moreover, the prior aim of such reduction in cognition is to be less subject to change. 
(IJRSSH) 2020, Vol. No. 10, Issue No. III, Jul-Sep

Researchers follow four paradigms so as to test the amount of dissonance in many situations.First,'Free Choice Paradigm' which is introduced by Brehm (1956: 384-89) that is in making decisions, negative and positive aspects are clashed, i.e., dissonance comes to exist in case of negative aspects of chosen alternative and the positive aspects of defeated them .What is naturally assumed is that the positive aspects are related to the chosen alternative and the negative aspects are related to defeated alternatives .In similar vien, Brehm asserts that difficult decisions create too much dissonance than that of simple ones.Dissonance can be reduced by purifying and throwing away negativity from the chosen alternatives, and adding the flavor of positivity instead. Or by taking the more preferable alternatives and neglecting the less ones in terms of 'spreading the alternatives'.

The second paradigm is known' Induced Compliance' which is introduced by Festinger and Carlsmith(1959:203-10) and is supposes that the action or behavior of a person in specific situation is contrasted to certain belief, attitude, or value in which the cognitions of such beliefs, let us say, never permit one to do so .The behavior of encouragement ( like rewards and profits) and punishment(like threats and fears)are ultimately cognitions which should be consistent with such behaviors.

\subsection{Rank's Models of Persuasion}

Hugh Rank (1976:5) may be a basic analyst who offers a impressive consider in considering two sorts of persuasion, promoting the significance of certain subject within the eyes of the peoples so as to persuade them to require activity, and down playing others .Rank (1991:17-21) presents this demonstrate in which two conflicting designs are gone to persuasive situations. They are" heightened and down play" designs in the sense that a persuader seeks to heighten his 'good' things or deeds and make light of his ' bad' ones .And conversely he tries to heighten the other' awful ' things or deeds and downplay their 'good ' ones .This sort of orientation isn't found in all individuals, so those who hone it ought to, to certain extent,be proficient ones. The designs are dynamic ,subjected to alter in case of sudden need, i.e ., a persuader may utilize reiteration in particular event
e-ISSN: 2249-4642, p-ISSN: 2454-4671

and time, then may utilize exclusion in other times for influential causes .Intensification (ibid) can be established by the use of repetition, association, or composition .By means of repetition,the persuadee isintensified to accept the persuasive messages.This way is simple and effective in the sense that people get pleasure with the well familiar and known topics, and hence avoiding the new and incomprehensive ones .Usually, selecting words that echo the strength is done by repetition. And by means of association, the persuader tends to connect his ideas with either the desired or hatred things intentionally.Thus , this way of intensification can be established either directly, or indirectly ,i.e., by the use of metaphoric language, background, or context .By means of composition, the persuader arranges and designs what is being presented. Using various words or images so as to achieve intensification in a systematic verbal communication. Downplay (ibid.)is the reverse form of intensification,people can do it by reversing the intensification means, nevertheless there are three ways to follow this pattern. By means of diversion, the persuader can divert or distract others for the sake of reducing the attention to certain topic. Instead, the focus attention on the trivial, superficial topics regardless the important ones. By means of omission, the persuader may hide certain things intentionally.He is pre-determined to what to include or exclude in his persuasive message, in political domain the use of cover-ups is dominant in most issues .Lastly, by means of confusion ,the persuader deliberately makes things messy and complex so as to overload the others, hence s/he persuades them to give up everything behind. Thus, the danger of this pattern lies in its consequence in making unreasonable decision.Inconsistencies, contradictions, faulty logic , and circumlocution are all causes of confusion.

\subsection{Information Manipulation Theory (IMT)}

McCornacks (1992:1-16) presents this theory which is based on the suspicion that the tricky message can be obviously or clandestinely kept up if the persuader lectures one of Grice's four maxims. While the discussion is assumed to be informative and completely caught on is ascribed to the' Quantity' proverb, being honest and total is attributed to the ' Quality' maxim, and being pertinent to combine basic 
measurements is credited to the ' Connection ' saying, and finally being concentrating on the way the data displayed is ascribed to the' Manner' maxim.Yeungetal.(1999:1-2) proposes that these maxims can be damaged within the sense that distorting data is due to the certain breach of quality.And lies of exclusion is due to the implicit breach of quantity while duplicity by shirking and confusion is due to the implicit breach of relevance and way.

Politicians follow certain strategies which can be critically tested. They may impose certain beliefs that are not acceptable, or marginalize certain segments of audience.Their ultimate aim is to manipulate others by offering unknown knowledge and the like.VanDijk(2005:73-82) assumes having k-device, i.e., knowledge device which depends largely on the amount of knowledge the interlocutors have in certain issue and the form of act is adopted respectively. In case of ambiguity, this device works so as to recall ,confirm, or presuppose it . what politicians do not confirm is assumed to be known by the public. They may presuppose knowledge beliefs which are in fact not credit or accepted but only pretending of its acceptance .In this case people can easily be manipulated by the new knowledge simply because it derives from high authority. Conversely, those elites can presuppose that their audience have no level of knowledge and treating them as ignorant .This aspect is widely used among white male elites, addressing women,or specific minorities .Moreover, there is what is called the abuse of contextual kdevice that is how elite discourse conveys knowledge by the media. In turn, it has its impact on distorting the fact that what they have reported is supposed to be true (Dijk,2005:88) .

\section{ATTITUDES, BEHAVIORS, AND BELIEFS: THE OUTCOMES OF PERSUASION}

Piere (1934:230-37) claims that the relationship between attitude and behavior is that of consistency,i.e., the behavior of an individual ought to match with his unsurprising state of mind, if not, or in term of irregularity ,there's something off-base either with the individual or with others .So, to bridge this crevice the persuader may elaborate a strategy to induce the adjust and the mental consolation.

Perloff(2003:38-41) suggests that attitude is known as a 'hypothetical construct' which is invisible concept but can be interpreted by people's actions .He explains that values and beliefs are two interrelated concepts in the area of persuasion " like attitudes,values and beliefs are learned and shapes the way we interpret information", because beliefs reflect the cognitions of the world, they have cognitive criteria rather than values and attitudes .Moreover, Perloff (ibid:45) mentions the relationship between attitudes and beliefs is that beliefs can be identified as components of attitudes and thus attitudes are complex components of beliefs and affection.Beliefs and values suggest the elaboration of rational model which is based on the fact that peoples' beliefs and values have impact on their behavior.Attitudes are psychological construct of the self which can be tested in terms of preferences whether to stand for or against certain issue; or to like or dislike other one.Hogg\&Vaughan(2005:150) define attitudes as "a relatively enduring organization of beliefs, feelings, and behavioral tendencies towards socially significant objects, groups, events or symbols". Carno (2001:340) elaborates that attitude formation and change are important issues related to persuasion, i.e., in a planned behavior the ultimate concern is essentially that of attitude as the construction of the self.

Ajzen\&Fishbein(2005:205) say that attitudes can be measured in term of the audiences' preferences towards the persuasive attempt .For instance, at the level of political persuasion if the topic is about the government policy,its policy is exposed and the choice of acceptance or rejection will be left on the part of the audience.In addition, attitudes towards candidate can be tested in terms of the audiences' approval or disapproval towards him. In aggregated judgment of certain attitude people depend heavily on the beliefs they have in different contexts.

Larson(2010:194) suggests that there are many features related to the concept of attitudes, first,they are not born with us, but rather they are learned and acquired through experience .Second, they are 
(IJRSSH) 2020, Vol. No. 10, Issue No. III, Jul-Sep

evaluation of an object such as person ,place ,or issue which affects actions .And finally since they are prepared to take a course of action, so they suggest behavior.Following these features, attitudes can be described in terms of three categories (Affect, Behavior, and Cognitive, henceforth $\mathrm{ABC}$ ). The affective category which refers to the personal feelings and emotions towards certain object .The behavioral category which refers to the way that attitudes act and behave. The cognitive category which refers to the personal knowledge and beliefs about certain issue.

Larson(ibid:198) says that attitudes are confined to change by the process of persuasion, and seemingly the intentional behavior brings inevitable change in attitude.Being conscious help people in understanding the attitudes of the persuaders' intentions and?. Moreover, realizing his attitudes make people decide whether his/her persuasive message is positive or not, ethical or not as well.Many scholars like (Abelson, Kinder, Peters, \& Fike,1981;Stangor , Sullivan\& Ford, 1991)suggest the idea that the same attitude may be hold differently by people for many reasons . This is obvious when people engage in voting for certain candidate .Voting is a matter of like or dislike and hence encourage the existence of multiple attitudes.In spite the fact that cognition is important to recognize attitudes,but the role of affect is more prominent, hence important and the strongest in voting decisions.

\section{REFERENCES}

Andersen,K.(1971) Persuasion: Theory and Practice. Boston: Allyn and Bacon.

Bettinghaus ,E.P.,\& M.J. Cody (1987) Persuasive Communication(4 ${ }^{\text {th }}$ ed.) New York Holt ,Rinehart and Winston.

Brembeck,W.L. \& Howell(1976)0 Persuasion :A Means of Social Influence .New Jercy: Prentice-Hall .Inc.

Chilton, P.A.(2004) Analyzing Political Discourse: Theory and Practice. London: Routledge.

Charles U. Larson (2010) Persuasion: Reception and Responsibility.(12 ed.). Northern Illinois University .Emeritus

Fazio,R. ,H., Jackson, J.R.,Dunton, B.C., \& Williams ,C.J.( 1995) . Variability in automatic activation as an unobtrusive measure of racial attitudes : A bona fide pipeline? Journal of Personality and Social Psychology, vol.69,pp.339-350.
e-ISSN: 2249-4642, p-ISSN: 2454-4671

In discussion the outcomes of the recursive nature of persuasion, one can easily discover that persuasion are attitudes, seek to change which comes to exist in a form of behavior .Attitudes mean what the individuals see, hear, and say things , following the definition of William James "they engender meaning up on the world" .Therefore, attitude and behavior reflect how people behave in this messy world.Behavior is considered "a gold criteria" since it reflects the core of the persuasive message .To test someone's real and actual behavior ask him/her whether their behaviors are true or not .Moreover, researchers cannot attend to the a scene like voting. Therefore, the majority studies on persuasion depend largely on the self-report of behavior. (Rhodes\&Ewoldsen,1997:200).

The extent that the audience holds an attitude plays a crucial role in establishing persuasion .The audience may interpret the persuasive message differently due to different beliefs and values and hence different attitudes. It is a matter of motive and ability that attitude change in relation to the Elaboration Likelihood Model (ELM) options, i.e., the nature of attitude change depends on which route the audience follow, the central or the peripheral one .In case of low motivation or ability, peripheral route becomes important to carry the persuasive load and thus the attitude change will be weak, short -lived and is about to submit behavior (Larson,2010:19596) . is something difficult as it is unethical sometimes to 
Festinger ,L., Riecken, H.W.,\&Schachter ,S.(1956).When prophecy fails.Minneapolis: University of Minnesota Press. In Harmon Eddie ,J: A Cognitive Dissonance, Theory Perspective on Persuasion. University of Wisconsin Al umni Research Foundation.

Frijda,N.,H. and Mesquita ,B. ( 2002) Beliefs through Emotions; (eds.), Cambridge University Press.

Green, M.C.,\& Brook ,T.C.(2005).Persuasiveness of narratives .In T.C. Brock ,( ed.)\&M.C. Green(eds.),Persuasion: Psychological insights and perspectives .

HandayaniMediana, DosenTidakTetap. (2011).Introduction to persuasion.p.4

Larson, Charles U. (2010) Persuasion: Reception and Responsibility.(12 ed.). Northern Illinois University .Emeritus.

Mc Curie, W.J.(1964). Inducing resistance to persuasion in contemporary approaches .

Matthews, P.H.(2005).Oxford Concise Dictionary of Linguistics. New York: Oxford. University Press.

O'Keefe, D.J.(1990).Persuasion : Theory and research .Newbury Park, CA: Sage.

(2003). Message properties, mediating states, and manipulation checks: Claims, evidence, and data analysis in experimental persuasive message effects research. Communication Theory, vol. 13 .

Perloff ,R.M. ( 2003).The Dynamics of Persuasion: Communication and Attitudes in the $21^{\text {st }}$ Century( $2^{\text {nd }}$ ed.). ISBN.

Rank ,Haugh(1976).Teaching about Public Persuasion ,In Daniel Dietrich (ed.),Teaching about Doublespeak, Illinois :National Council of Teachers of English .

(1991).The Pitch: How to analyze Ads. $2^{\text {nd }}$ edition .USA publication.

Rhodes,N.,\&eWoldsen, D.R.(1997).Attitude accessibility and persuasion: Review and a transactive model. In B Burleson (ed.), Communication Yearbook20.Beverly Hills, CA: Sage.

Scudder Joseph N. Social Scientific approach to persuasion . In Charles U. Larson (2010) Persuasion: Reception and Responsibility.(12 ed.). Northern Illinois University .Emeritus.

Sexton, Jeff (2010).Powerful Social Media Persuasion Techniques..Free Social Media Marketing Industry Report. February 11. Website Optimization .pp. 1-3.

Smith,M.,J. (1982) Persuasion and Human Action: A Review and critique of Social Influence Theories. Belmont,CA: Wadsworth.

Stacy Wedia, Karl Stolley,(2013),Feb.11, 12:56:30. Using Rhetorical Strategies for Persuasion.P.1-2

Straker, David (2016) How we can change what others think, feel ,believe and do. Three types of Persuasion .Changing Minds Org. In Changing Minds in detail.pp. 1-3 . 
(2012) How we can change what others think ,feel, believe and do. Rank's Intensify/ Downplay Schema. Changing Minds Org. In Changing Minds in detail.pp. 1-3.

-------------(2016)How we can change what others think ,feel, believe and do .Four Persuasion Styles. Changing Minds Org.In Changing Minds in detail .pp. 1-4 .

Stranzy ,Ph(2005).Encyclopedias of Linguistics .New York: Taylor and Francis book. Inc.

Thornborrow , Joanna ( 2001) Power Talk. Language and Interaction in Institutional Discourse.Longman. England. London. New York.

Vanderveken\& Susumu Kubo(2001).Essays in Speech Act Theory (eds.) John Benjamins , Amsterdam Philadelphia.

Westen Drew(2007). The Political Brain :The role of emotion in deciding the fate of the nation..New York, NY .Public Affairs Books.

Worthington, Ian( 1994).Persuasion: Greek Rhetoric in Action. Publication in the USA And Canada by Rutledge. 